\title{
A Study on Fabrication of Zinc Oxide thin Film Acoustic Sensors
}

\author{
C.C. Chang \\ Associate Professor, Departent of Electrical Engineering, National Taiwan Ocean University, Keelung, Taiwan. \\ J.H. Chang \\ Graduate Student, Department of Electrical Engineering, National Taiwan Ocean University, Keelung, Taiwan.
}

Follow this and additional works at: https://jmstt.ntou.edu.tw/journal

Part of the Electrical and Computer Engineering Commons

\section{Recommended Citation}

Chang, C.C. and Chang, J.H. (1996) "A Study on Fabrication of Zinc Oxide thin Film Acoustic Sensors," Journal of Marine Science and Technology. Vol. 4: Iss. 1, Article 17.

DOI: $10.51400 / 2709-6998.2550$

Available at: https://jmstt.ntou.edu.tw/journal/vol4/iss1/17

This Research Article is brought to you for free and open access by Journal of Marine Science and Technology. It has been accepted for inclusion in Journal of Marine Science and Technology by an authorized editor of Journal of Marine Science and Technology. 


\title{
A STUDY ON FABRICATION OF ZINC OXIDE THIN FILM ACOUSTIC SENSORS
}

\author{
C.C. Chang* and J.H. Chang**
}

Keywords: ZnO thin film, acoustic sensors.

\section{ABSTRACT}

In this study, acoustic sensors were formed by depositing a zinc oxide $(\mathrm{ZnO})$ thin film on a silicon dioxide/silicon( $\mathrm{SiO} / \mathrm{Si})$ substrate using radio frequency (RF) planar-magnetron sputtering method. The results showed higher substrate temperatures and higher RF powers enhanced $\mathrm{C}$-axis oriented structure of the $\mathrm{ZnO}$ thin film and optimized the $\mathrm{ZnO}$ thin film acoustic property. The frequency spectrum measurement on the acoustic sensor underwater involved three peaks at frequencies $640 \mathrm{KHz}, 2.4 \mathrm{MHz}$ and 2.9 $\mathrm{MHz}$, respectively. Sensitivity reached to $-132.02 \mathrm{dBrelv} / \mu \mathrm{pa}$. The results indicated that under the pressure of acoustic frequencies the sensor response was directly proportional to pressure and, therefore, can be actually utilized in underwater sounding tests.

\section{INTRODUCTION}

In zero or low visibility environments, acoustic devices are superior to optical devices in the detection of targets. Therefore, ultrasonic sensors and sonar are crucial to the development of submarine technologies. Since conventional acoustic sensors or transmitters are constructed of bulky ceramic materials, they have imposed severe restrictions on the development of acoustic systems. With the aid of integrated circuit (IC) technology to develop intelligent acoustic sensors, many researchers have recently begun to develop thin film acoustic sensors [1-3].

$\mathrm{ZnO}$ is a piezoelectric material that can be fabricated into thin film for intelligent acoustic sensor applications. The material can be deposited on various types of substrates[4,5]. The use of silicon materials as the substrate enables integration of intelligent

Paper Received March, 1996. Revised June, 1996. Accepted June, 1996. Author for Correspondence: C.C. Chang.

*Associate Professor, Department of Electrical Engineering, National Taiwan Ocean University, Keelung, Taiwan.

**Graduate Student, Department of Electrical Engineering, National

Taiwan Ocean University, Keelung, Taiwan. acoustic systems onto a chip through IC techniques. In this study, $\mathrm{ZnO}$ served as the source material for the thin film acoustic sensor and was deposited on a $\mathrm{SiO}_{2} /(100) \mathrm{Si}$ substrate, with aluminum(Al) utilized as the electrode. To improve sensitivity, the quality of the $\mathrm{ZnO}$ thin film used on acoustic sensors must be optimized. The optimization parameters included oxygen contents, RF power and substrate temperature [5], which were analyzed to study $\mathrm{ZnO}$ deposition conditions. Since the acoustic sensor was layered on a Si substrate, the placement of an IC on the same single chip to configure an intelligent sensor was not a difficult task.

\section{EXPERIMENTAL PROCEDURES}

Referring to the fabrication process of the $\mathrm{ZnO}$ thin film sensor in Figure 1, a $\mathrm{Si}(100)$ wafer was coated with $\mathrm{SiO} 2$ (Fig. 1a). A substrate window was created through the optical lithography(Fig. 1b) and after anisotropic etching the diaphragm was made in the Si substrate with EDP solution(Fig.1c, Fig. 1d) [6]. Furthermore, Al was utilized as the rear electrode material. With an $\mathrm{Al}$ deposition thickness of approximately $1,000 \AA$, the electrode pattern was accomplished(Fig. 1e) through the same lithographic technique shown in Fig. 1b. The $\mathrm{ZnO}$ thin film material was then deposited on the $\mathrm{Al} / \mathrm{SiO}_{2} / \mathrm{Si}$ substrate with an RF planar magnetron sputter (Fig. 1f). Next, the Al front electrode and electrode pattern were also completed using the same lithographic technique(Fig. 1f). Following the etching of patterns(Fig. $1 \mathrm{~h}$ ) on the $\mathrm{ZnO}$, the fabrication of the sensor was complete. Fig 1i was the top view of the $\mathrm{ZnO}$ thin film acoustic sensor. Since Al was utilized as the rear electrode in the experiment, $\mathrm{ZnO}$ thin film deposited on $\mathrm{SiO}_{2} / \mathrm{Si}$ substrate and $\mathrm{Al}$ electrode needed to be considered at the same time. In this paper, the experimental variables used are oxide contents of $0 \%$ to $50 \%$, substrate temperatures of room temperature to $350^{\circ} \mathrm{C}$ and $\mathrm{RF}$ power from 80 watts to 200 watts. The quality of $\mathrm{ZnO}$ thin film 
structure was analyzed with XRD. Moreover, the characteristics of the acoustic sensor were measured in an underwater condition to find out its frequency spectrum and thereby determine the quality of the $\mathrm{ZnO}$ thin film acoustic sensor using reciprocity method.

\section{RESULTS AND DISCUSSION}

Since the high degree of $\mathrm{C}$-axis oriented or high degree of (002) preferred polycrystalline structure of $\mathrm{ZnO}$ thin film can enhance its piezoelectric properties [7-10]. The piezoelectric properties of high degree of $\mathrm{C}$-axis oriented structure is similar to the piezoelectric properties of $\mathrm{ZnO}$ single crystal. How to enhance the degree of $\mathrm{C}$-axis oriented is important for high sensitivity $\mathrm{ZnO}$ thin film acoustic sensor. In addition, the smaller full width at half maximum intensity (FWHM) also has better structure quality of $\mathrm{ZnO}$ thin film and can improve the quality of $\mathrm{ZnO}$ thin film acoustic sensor.It is very important to have higher degree of $\mathrm{C}$-axis oriented structure and lower FWHM value of $\mathrm{ZnO}$ thin film for high senstivity $\mathrm{ZnO}$ thin film acoustic sensor.

The (002) peak FWHM of $\mathrm{ZnO}$ thin film which deposited at different temperatures on $\mathrm{SiO}_{2} /(100) \mathrm{Si}$

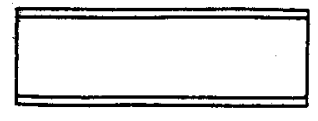

(a) Substrate

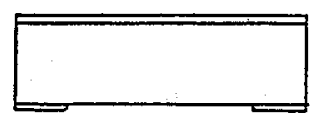

(b) $\mathrm{SiO}_{2}$ etch

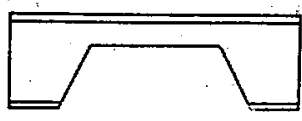

(c) Anisotropic etch

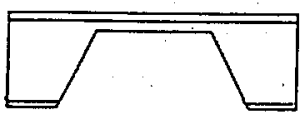

(d) Si diaphram

(e) Al electrode deposition

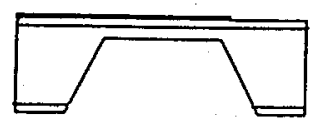

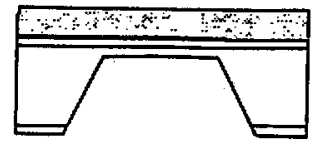

(f) $\mathrm{ZnO}$ thin film deposition

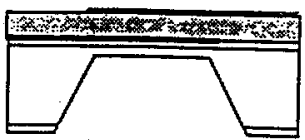

(g) Al electrode deposition

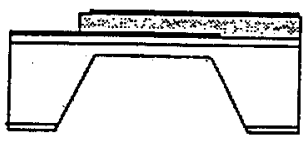

(h) $\mathrm{ZnO}$ etch

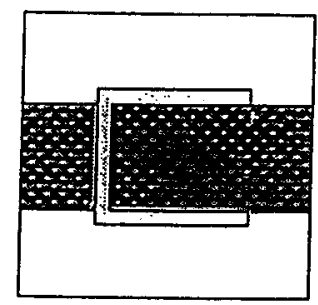

(i) Top view of the $\mathrm{ZnO}$ sensor
Fig. 1. Fabrication procedure of the $\mathrm{ZnO}$ thin film acoustic sensor. substrate from X-ray diffraction patterns (XRD) are shown in Fig. 2. Higher deposition temperatures improved the crystallinity of $\mathrm{ZnO}$ thin film, since the FWHM value of the $\mathrm{ZnO}$ thin film is reduced. Different RF powers showed similar results. Therefore, higher deposition temperatures effectively improved the sensitivity of $\mathrm{ZnO}$ thin film acoustic sensors consisting of $\mathrm{ZnO}$ thin film layered on $\mathrm{SiO}_{2}$ / (100)Si substrates[5]. As indicated in Fig. 3, similar

\section{FWHM( $\left(^{\circ}\right)$}

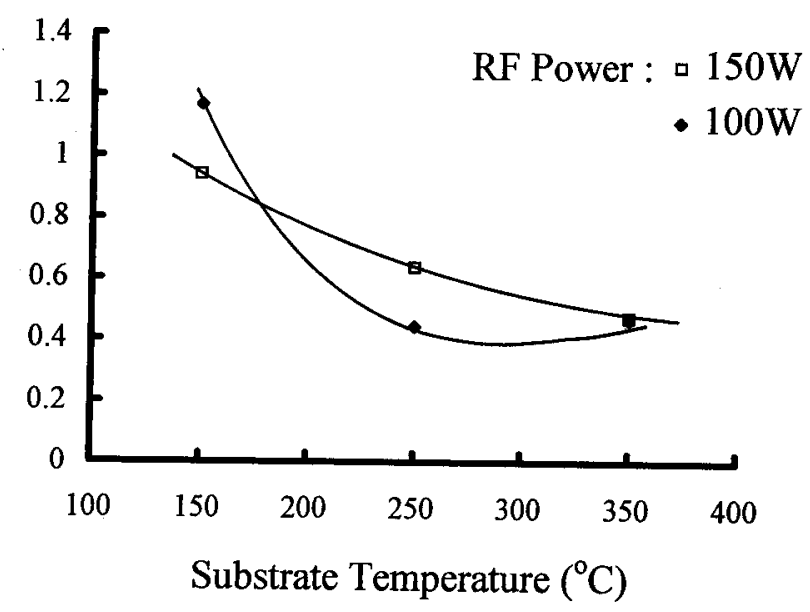

Fig. 2. The (002) peak FWHM of X-ray diffraction patterns of $\mathrm{ZnO}$ thin films on $\mathrm{SiO}_{2} /(100) \mathrm{Si}$ substrate grown at 100 and 150 watts $\mathrm{RF}$ power with different substrate temperatures.

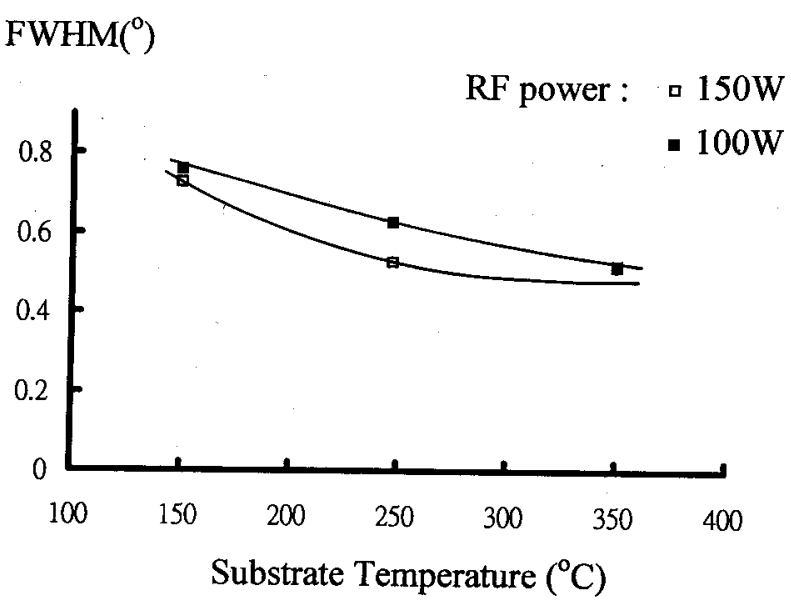

Fig. 3. The (002) peak FWHM of X-ray diffraction patterns of $\mathrm{ZnO}$ thin films on Al electrode grown at 100 and 150 watts RF power with different substrate temperatures. 
findings were observed when $\mathrm{ZnO}$ thin film was deposited onto an $\mathrm{Al}$ electrode. In addition, Fig. 4 shows the relationship between the degree of (002) preferred orientation of $\mathrm{ZnO}$ thin film on $\mathrm{SiO}_{2} /(100) \mathrm{Si}$ substrate and oxygen contents at different magnitudes of RF power, where the degree of the (002) preferred orientation structure was based on XRD data of the $\mathrm{ZnO}$ thin film. Sum of count values of peaks $(002)$ and peaks (004) with respect to these of all diffraction peaks of $\mathrm{ZnO}$ thin film from XRD in the $2 \theta$ from $30^{\circ}$ to $70^{\circ}$ was used to determine the degree of $(002)$ preferred orientation structure of $\mathrm{ZnO}$ thin film on $\mathrm{Si}$ substrate. According to this figure, the effect of the oxygen content on the degree of $\mathrm{C}$-axis oriented structure of $\mathrm{ZnO}$ thin film was relatively small, and increase in RF power(more than 110 watts) achieved a superior $\mathrm{C}$-axis oriented structure of $\mathrm{ZnO}$ thin film that is very beneficial to the sensitivity of acoustic sensor. Fig. 5 is the relationship between (002) preferred orientation of $\mathrm{ZnO}$ thin film on $\mathrm{SiO}_{2} /(100) \mathrm{Si}$ substrate and oxygen contents at different substrate temperatures. According to the figure,the effect of the oxygen content on the degree of $(002)$ preferred polycrystalline structure of $\mathrm{ZnO}$ thin film was relatively small when the substrate temperature was higher than $200^{\circ} \mathrm{C}$. Furthermore, the degree of $(002)$ preferred structure of $\mathrm{ZnO}$ thin film was near $100 \%$ when the substrate temperature was at $200^{\circ} \mathrm{C}$. The $\mathrm{ZnO}$ thin film on Al electrode had similar results. It seems that the higher deposition temperature and RF power at $110 \mathrm{~W}$ or above are better to achieve higher sensitivity of $\mathrm{ZnO}$ thin film acoustic sensor. To optimize the $\mathrm{ZnO}$ thin film deposition on $\mathrm{SiO}_{2} /(100) \mathrm{Si}$ substrate and $\mathrm{Al}$ electrode, the RF power applied in this experiment was 150 watts

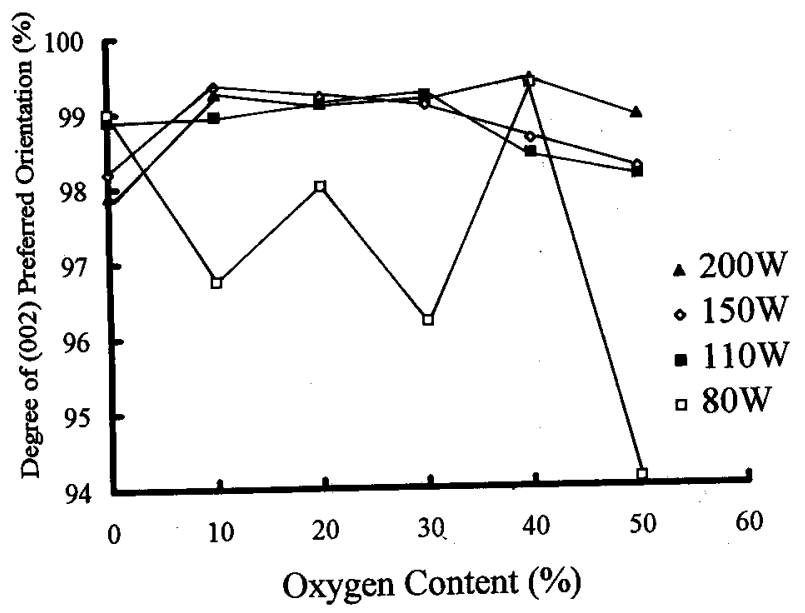

Fig. 4. Degree of (002) prefered orientation as a function of oxygen content different RF powers. and the substrate temperature was $350^{\circ} \mathrm{C}$.

The optimized $\mathrm{ZnO}$ thin film was then fabricated following the device processes illustrated in Fig. 1 to produce the $\mathrm{ZnO}$ thin film acoustic sensor. Fig. 6 shows the frequency spectrum of the $\mathrm{ZnO}$ acoustic sensor, which was fabricated according to the process illustrated in Fig. 1. These $\mathrm{ZnO}$ acoustic sensors were produced utilizing the optimal parameters of $\mathrm{ZnO}$ thin film deposition and their respective frequency spectrums were measured underwater. Four $\mathrm{ZnO}$ thin film acoustic sensors of different size were compared in this experiment. The dimensions are indicated in Table 1. Sensor A,B have larger film area than sensor C,D. On the other side, sensor B,D have thicker $\mathrm{ZnO}$ thin film than sensor A,C. From the frequency spectrum, it reveals a similarity in the respective spectrums. These samples have the same

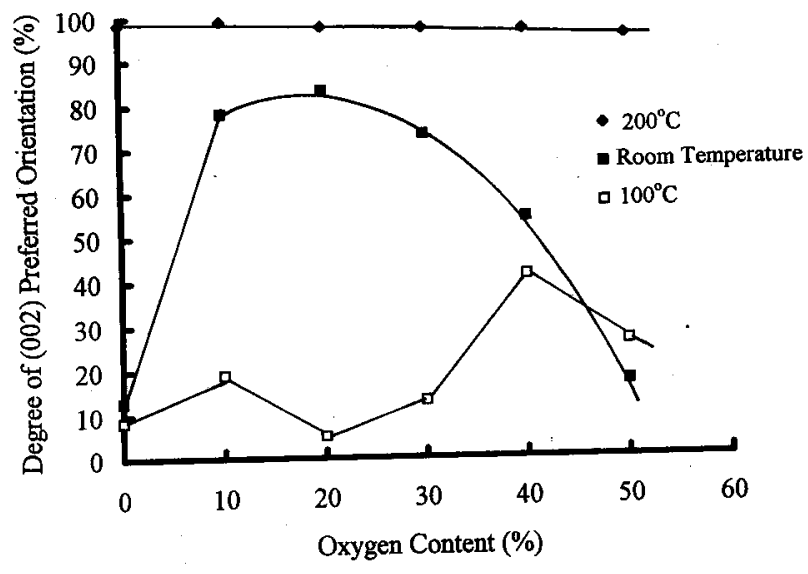

Fig. 5. Degree of (002) preferred orientation as a function of oxygen content with different deposition temperatures.

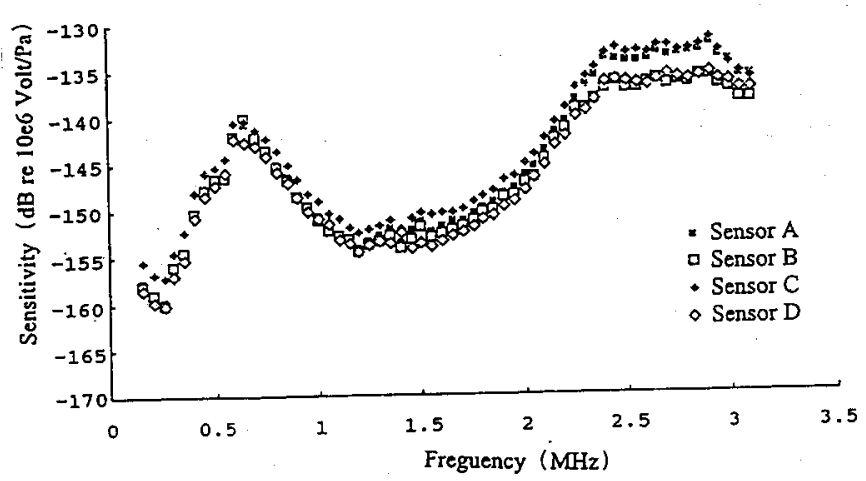

Fig. 6. Frequency spectrum of the $\mathrm{ZnO}$ thin film acoustic sensors at different structural scales. 
Table 1 The respective geometrical dimension of film layers for sensors $A, B, C$ and $D$.

\begin{tabular}{ccccc}
\hline & Sensor A & Sensor B & Sensor C & Sensor D \\
\hline $\begin{array}{c}\mathrm{ZnO} \text { film } \\
\text { thickness } \\
(\mu \mathrm{m})^{2}\end{array}$ & 8.6 & 12.2 & 8.6 & 12.2 \\
$\begin{array}{c}\mathrm{SiO}_{2} \text { film } \\
\text { thickness } \\
(\mu \mathrm{m})^{2}\end{array}$ & 0.5 & 0.5 & 0.5 & 0.5 \\
$\begin{array}{c}\text { Si diaphram } \\
\text { thickness } \\
(\mu \mathrm{m})^{2}\end{array}$ & 9.5 & 9.5 & 9.5 & 9.5 \\
$\begin{array}{c}\text { film area } \\
(\mu \mathrm{m})^{2}\end{array}$ & $(980)^{2}$ & $(980)^{2}$ & $(580)^{2}$ & $(580)^{2}$ \\
\hline
\end{tabular}

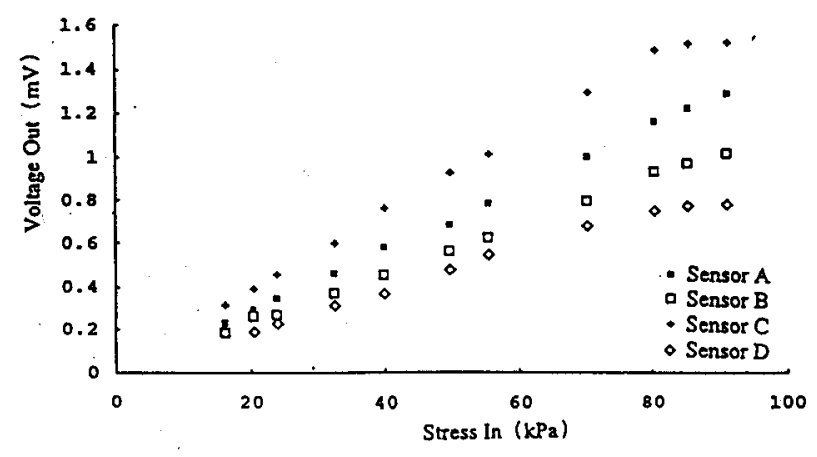

Fig. 7. Output voltage as a function of sonic wave input stress on the acoustic sensor at the frequency of $2.25 \mathrm{MHz}$.

peaks response, $650 \mathrm{KHz}$, $2.4 \mathrm{MHz}$. and approximately $2.9 \mathrm{MHz}$. The maximum sensitivity of sensor A, sensor B, sensor C and sensor D is $-132.02 \mathrm{dBrelv} /$ $\mu$ pa at $2.9 \mathrm{MHz},-135.98 \mathrm{dBrelv} / \mu \mathrm{pa}$ at $2.85 \mathrm{MHz}$, $-132.03 \mathrm{dBrelv} / \mu \mathrm{pa}$ at $2.9 \mathrm{Mhz}$ and $-135.62 \mathrm{dBrelv} /$ $\mu$ pa at $2.9 \mathrm{MHz}$, respectively, with a reference level of $0 \mathrm{dBrelv} / \mu$ pa. Based on the figure, the thinner film had a higher sensitivity. In addition, a smaller film area yielded a higher sensitivity in the high frequency range also that may be related to the mechanical vibration characteristics of $\mathrm{ZnO}$ thin film. Fig. 7 shows the sensor output voltages as function of input sonic pressure at the frequency of $2.25 \mathrm{MHz}$. The voltage output showed a linear variation with the sonic pressure when the pressure was less than 80 Kpa. It seems that the sensor sensitivity is correlated to input sonic pressure. However, when the sonic pressure exceeds $80 \mathrm{Kpa}$, sensitivity decreased due to the thin film vibration saturation. The findings reveal that under an appropriate range of pressure applied, the thin film acoustic sensors fabricated in this study will not pose any difficulties in practical applications.

\section{CONCLUSIONS}

Semiconductor fabrication process and the $\mathrm{Si}$ micromachining techniques were utilized to fabricate the thin film acoustic sensor in this study, wherein a $\mathrm{ZnO}$ thin film was deposited on $\mathrm{SiO}_{2} /(100) \mathrm{Si}$ substrate and an Al electrode by RF planar-magnetron sputtering method. The optimal prefered $(002)$ orientation of the $\mathrm{ZnO}$ thin film was achieved under the condition, substrate temperature $350^{\circ} \mathrm{C}$, RF power $150 \mathrm{~W}$. The frequency spectrum of the $\mathrm{ZnO}$ thin film acoustic sensors in this experiment have three peaks of approximate $650 \mathrm{KHz}, 2.4 \mathrm{MHz}$ and $2.9 \mathrm{MHz}$ with the optimal sensitivity of $-132.03 \mathrm{dBrelv} / \mathrm{pa}$. Moreover, the results revealed the effects of film geometrical dimension on sensor sensitivity. The sensitivity increased as the $\mathrm{ZnO}$ thin film thickness was reduced and as the film area was decreased. In addition, when subjected to an appropriate magnitude of sonic pressure $(<80 \mathrm{Kpa})$ the sensitivity of the thin film sensor was proportional to the sonic pressure.

\section{REFERENCES}

1. J. Bergqvist and F. Rudolf, Sensors and Actuators, A21-23, pp. 123-125 (1990).

2. M. Royer, J.O. Hlmen, M.A. Wurm, O.S. Aadland, Sensors and Actuators, 4, pp. 357-362 (1983).

3. E.S. Kim and R.S. Muller, IEEE Electron Device Letters, Vol. EOL-8, No. 10 , pp. 467-468 (1987).

4. C.C. Chang, J.H. Chang and S.K. Fang, "The Study of the Influence of sputtering Parameters and Substrates to ZnO Thin Film Structure", Chinese Journal of Material Science, Vol. 26, No. 1, p. 59 (1994).

5. C.C. Chang, C.T. Liou, "The study in the Characteristics of the ZnO Thin film on Metal Electrode", Proceedings of the 1994 Annual Conference of the Chinese society for Materials Science, Kaohsiung, p. 138 (1994).

6. A. Bohg, "Ethylene Diamine-pyrocatechol-water Mixture Shows Etching Anomaly in Boron Doped Silicon", J Electrochem. Soc., Vol. 118, p. 401 (1971).

7. T. Shposakiand and A. Kawabata, Ferroelectrics, 42, p. 219 (1982).

8. J.D. Larson, D.K. Winslow and L.T. Eitelli, IEEE. Trans Sonic Ultroson, SU-19, p. 18 (1972).

9. F.S. hickernell, J. Appl. Phys, 44, p. 106 (1973).

10. S.B. Krupanidhi and M. Sayer, J. Appl. Phys, 56 (11), p. 3308 (1984). 


\title{
氧化鋅薄膜音波元件製作研究
}

\author{
張忠誠張竟宏
}

國立台瀿海洋大受電機工程學系

$$
\text { 摘 要 }
$$

本埨文以射頻磁控淢射系統於 $\mathrm{SiO}_{2} /(100) \mathrm{Si}$ 基 板上沈積氧化锌薄膜, 配合蝕刻技街製作氧化锌薄 膜音波感测。由霓驗結果可知, 较高的射頻功率和 較高的氧化锌薄膜沈積温度可提界氧化锌薄膜之C 軸配向性, 也因此可得到高需敏度之氧化锌薄膜水 下音波感测元件。由頻譜之測量可知, 以不同薄膜 厚度及薄膜面積所製作之元件在 $640 \mathrm{KHz}, 2.4 \mathrm{MHz}$ 和 $2.9 \mathrm{MHz}$ 皆有峰值䅧應, 而较薄及較小面積之薄膜

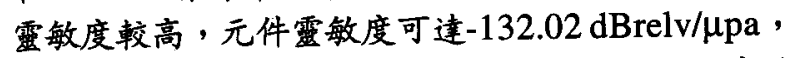
另外由於元件之警應和音波歷力成正比，因此富验 所製作之元件可實際應用於水下音波之偵测。 